\title{
Biological diversity of the bacterial community of the Vostok bay (Japan Sea) by high-throughput sequencing
}

\author{
Y. Golozubova*, L. Buzoleva, E. Bogatyrenko \\ Far Eastern Federal University, Vladivostok, Russia \\ *e-mail: know-26@mail.ru
}

Key words: Japan Sea, bacterial communities, anthropogenic pollution

\begin{abstract}
Motivation and Aim: The biodiversity of the microorganisms of the seas is insufficiently studied. About $99 \%$ of bacteria are noncultivated forms [1]. The application of the method of high-throughput sequencing allows obtaining the most complete data of the taxonomic structure and spatial distribution of bacterial communities. However, metagenome analysis of Japan Sea wasn't done.
\end{abstract}

Methods and Algorithms: The material for the work was samples of surface waters, selected in August 2015 in the Vostok Bay of the Japan Sea. A sample of sea water was taken with a syringe at a depth of $10-15 \mathrm{~cm}$, and 1.51 of sea water was filtered through membrane polycarbonate filters with a pore diameter of $0.22 \mu \mathrm{m}$ (Millipore, USA), fixing in $80 \%$ ethanol. The total DNA from the samples was isolated using the Amplipram DNA-sorb B kit according to the manufacturer's protocol with modification [2]. Taxonomic analysis was carried out based on the study of the V3-V4 variable region of the 16S rRNA gene. Amplification and metagenomic sequencing of 16S rRNA was performed on the MiSeq genomic sequencer of Illumina at the Genomics Center in Novosibirsk. The data obtained was analyzed using the Mothur software package, the Silva database.

Results: Analysis of the data showed that the prokaryotic community of the Vostok Bay was formed by the bacteria of the Proteobacteria (56\%) and Bacteroidetes (29\%), Actinobacteria (3\%) and Firmicutes (2\%) in the Vostok Bay. Our experiments also indicate that the families Flavobacteriaceaeae, Rhodobacteriaceae, occupy the dominant part of the microbial community.

Conclusion: Thus, with the use of metagenomic analysis in Japan Sea, the predominance of typical marine representatives of the phylum Proteobacteria, Bacteroidetes with prevalence of Alphaproteobacteria and Gammaproteobacteria.

Acknowledgements: Supported by the Russian Science Foundation (Agreement No. 14-50-00034).

\section{References}

1. Ravin N.V., Mardanov A.V., Skryabin K.G. (2015) Metagenomics as a tool for the investigation of uncultured microorganisms. Russian Journal Genetics. 51:431-439.

2. Belkova N.L. (2009) Modified technique for isolating total DNA from aqueous samples and ground extracts by the enzymatic lysis method. Molecular and genetic methods for the analysis of microbial communities. Diversity of microbial communities in inland water reservoirs of Russia: Printhouse. 53-63. 